\title{
The influence of Nonlinearity and Reactive Flow of Electronic Loads on the bus of Consumer Units and the Concessionaire
}

\author{
Lucas de Oliveira Rosa ${ }^{1}$, Acad.; Marllon Welter Schlischting ${ }^{1}$, Acad.; Gabriela Pessoa Campos ${ }^{1}$, Acad.; Iago de Moura \\ Faria $^{1}$, Acad.; Arnulfo Barroso de Vasconcellos ${ }^{1}$, Dr.; Teresa Irene Ribeiro de Carvalho Malheiro ${ }^{2}, \mathrm{PhD}$. \\ ${ }^{1}$ Faculty of Architecture, Engineering and Technology, UFMT -Federal University of Mato Grosso - Cuiabá/MT - Av. \\ Fernando Correa da Costa, 2367, Cuiabá (Brazil) \\ Phone: +55 (65) 3615-8000, e-mail: lucas_lor_@live.com, marllon.schlischting@gmail.com, \\ gabriela_pessoacampos@hotmail.com, iago_mf@hotmail.com, arnulfo@ufmt.br.
}

${ }^{2}$ Federal Institution of Education, Science and Technology of Mato Grosso - IFMT - Av. Sen. Filinto Müller , 953, Cuiabá (Brazil)

Phone: +55 (65) 3616-4100 ,e-mail: malheiro.teresa@ gmail .

\begin{abstract}
.
The main focus of this article is to analyze the profile of LED lamps, tubular and compact, present in Consumer Units from groups A and B. The current technological advances led to increasing use of electronic loads in all sectors, mainly in residential and commercial consumers. In laboratory measurements using LED lamps, it was observed that the reactive power flow injected into the bar is equivalent or greater than the power flow consumed by the lamps, thus influencing the power factor of the electrical system. This paper presents measurements on electronic loads, composed of LED lamps, common in Consumer Units and analyzes its influence on the charging system and power quality.
\end{abstract}

\section{Key words}

Electrical efficiency, power quality, reactive power flow, LED Lamps, Fluorescent Lamps.

\section{Introduction}

The quality of electricity delivered by the distributors to consumers has always been an object of interest. However, until some time ago, the electric power quality was associated, mainly, with the continuity of distribution services based on system availability and network parameters. Thus, a system state study was needed to identify ways to keep the quality in the operating system.

However, the growing trend of electronics provided the increase use of electronic equipment's, introducing in the electrical system a large number of electronic charges, so that the studies to be conducted in an electrical system cannot ignore the influence of such loads and its consequences. For example, when performing the studies of power flow in a system, they always led to the use of linear elements, capacitor bank and inductors, for reactive compensation and control of voltage level. However, analyzing the behavior of certain electronic loads, there is a capacitive reactive flow that can behave as an internal compensation system.

The reactive compensation through electronic loads present in the system would impact the performance of this and also in excess of billing reactive energy, especially in predominantly inductive systems. As it is known, large consumers are penalized by excess reactive energy tariff, for example, industries that operate with a significant number of induction motors with power factor lower than that established by standards. In this sense, the reactive flow behavior of electronic loads can help in reactive compensation, decreasing the amount of capacitor bank to be installed.

Thus, this article aims to analyze the reactive power flow of electronic loads, specifically compact and tubular lamps LEDs [1].

\section{Considerations regarding reactive power over the electric system}

The Normative Resolution no. 414 [2], of 9 September 2010, lays down the general conditions for the supply of Electricity in an updated and consolidated basis, it says that to consumers of Group A, the reference power factor "fr" , inductive or capacitive, have minimum allowed limit, the value of 0.92 .

"At electricity amounts and reactive power demand exceeding the allowed limit, apply the charges set out in articles 96 and 97, to be added to regular sales of consumer units in group $\mathrm{A}$, including those who choose revenue from the application of Group B tariff under article 100. "(Normative Resolution no. 414, 2010, p. 84)

"Article 96. - For a Consumer Unit that has appropriate measuring equipment, including one whose owner has signed the CUSD, the values corresponding to electricity and excess reactive power demand are calculated according to the following equation: "(Normative Resolution no. 414, 2010, p . 84-87). 


$$
\begin{aligned}
& E_{R E}=\sum_{T=1}^{\pi 5}\left[E E A M_{T} \times\left(\frac{f r}{f t}-1\right)\right] \times V R_{E R E}(1) \\
& D_{R E}(p)=\left[\operatorname{MAX}_{T=1}\left(\text { PAM }_{T} \times \frac{f r}{f t}\right)-P A F(p)\right] \times V R_{D R E}
\end{aligned}
$$

\section{Where:}

$\mathrm{E}_{\mathrm{RE}}$ : amount corresponding to the reactive power over the amount allowed by the reference power factor "fr" in the billing period in Reais ( $\mathrm{R} \$$ );

EEAM $_{\mathrm{T}}$ : amount of active power measured at each interval " $\mathrm{T}$ " of one (1) hour during the billing period in Megawatt-hour (MWh);

fr: reference power factor of 0.92 ;

$\mathrm{ft}$ : power factor of the consumer unit, calculated at each interval " $\mathrm{T}$ " of one (1) hour during the billing period;

$\mathrm{VR}_{\mathrm{ERE}}$ : reference value equivalent to the energy tariff "TE" applicable to subgroup B1, in reais per megawatthour (R \$ / MWh);

$\mathrm{D}_{\mathrm{RE}}(\mathrm{p})$ : value, tariff position "p", corresponding to the demand for reactive power over the amount allowed by the reference power factor "fr" in the billing period in Reais (Brazilian currency R \$);

$\mathrm{PAM}_{\mathrm{T}}$ : active power demand as the payment interval of one (1) hour "T" during the billing period in kilowatt $(\mathrm{kW})$;

$\operatorname{PAF}(\mathrm{p})$ : Demand billable active power in each tariff position " $\mathrm{p}$ " in the billing period in kilowatt $(\mathrm{kW})$;

$\mathrm{VR}_{\mathrm{DRE}}$ : reference value, in reais per kilowatt $(\mathrm{R} \$ / \mathrm{kW})$, equivalent to the power demand rates for the tariff put off tip of supply tariffs applicable to subgroups of group A for the Blue hourly tariff mode and TUSD - free consumers, as is in force the Supply Agreement or the CUSD respectively;

MAX: function that identifies the maximum value of the equation within the brackets corresponding in each tariff position "p";

$\mathrm{T}$ : Indicates interval of one (1) hour in the billing period;

p: Indicates tip tariff position or off-peak to the hourly tariff arrangements or billing period for conventional tariff mode binomial;

$\mathrm{n} 1$ : number of intervals of payment " $\mathrm{T}$ " of the billing period for tariff positions tip and off-peak;

$\mathrm{n} 2$ : number of intervals of payment "T" for tariff position "p" in the billing period.

Therefore, even though the amount to be paid is related to reactive surplus, this is proportional to the amount of active power measurement in the time interval related to the measurement and the relationship of the reference power factor to unity power factor consumer.

For the calculation of these quantities, there is also a period of six (6) consecutive hours (at the discretion of the distributor) between $23 \mathrm{~h} 30 \mathrm{~min}$ and $6 \mathrm{~h} 30 \mathrm{~min}$, which considers only the power factors "ft" less than 0.92 capacitive, checked at each interval of one hour "T". Complementing daily period, it is considered only the power factors below 0.92 inductive, recorded in the same time.
As the loads studied in this work are electronics and capacitive nature, there is a direct influence on its use with the measurement of excess reactive values described in the resolution rules, because they, in theory, injecting capacitive reactive on the bus, contribute to the change in value of the power factor measured every hour. This raises new discussions in the academic world about how relevant is this influence, due to the considerable increase of electronic loads in the residential, commercial and industrial buses.

\section{Considerations relating to harmonic distortion in electrical systems}

For basic energy network, the National System Operator (ONS) provides, since 2002, quality parameters for the supplied voltage. But from the consumer's viewpoint, the restrictions to consider are (mostly) the distribution system, which are still in discussion.

The National Electric Energy Agency (ANEEL), in the "electricity distribution procedures in the national electric system - PRODIST Module 8 - Power Quality" [3] proposes references values for the harmonic voltage distortion in the system distribution, as shown in Table I.

Table I. - DTT Reference Values

\begin{tabular}{|c|c|}
\hline $\begin{array}{c}\text { NOMINAL VOLTAGE } \\
\text { BUS }\end{array}$ & $\begin{array}{c}\text { TOTAL HARMONIC } \\
\text { DISTORTION } \\
\text { VOLTAGE [\%] }\end{array}$ \\
\hline $\mathrm{Vn} \leq 1 \mathrm{kV}$ & 10 \\
\hline $1 \mathrm{kV} \leq \mathrm{Vn} \leq 13,8 \mathrm{kV}$ & 8 \\
\hline $13,8 \mathrm{kV} \leq \mathrm{Vn} \leq 69 \mathrm{kV}$ & 6 \\
\hline $69 \mathrm{kV} \leq \mathrm{Vn} \leq 138 \mathrm{kV}$ & 3 \\
\hline
\end{tabular}

The LED lamp used in the laboratory experiment show nonlinear characteristics, which results in current waveforms with significant distortions. However, to the tensions in the supply of bus loads, there was no significant harmonic distortion, remaining within the limits recommended by rules established by ANEEL Resolution [4]. Thus, regardless of electronic charge be linear or nonlinear, the reactive power flow behavior is presented in the direction of the load to the source, characterized capacitive reactive power flow.

The equipment used to record the electrical parameters of the lamps in the laboratory correspond to MARH-21 power quality analyzer RMS manufacturer, illustrated in Fig. 1 and Fluke434, which are real-time magnitudes registers meters for single-phase, two-phase electrical systems and three-phase in low, medium and high voltage. 


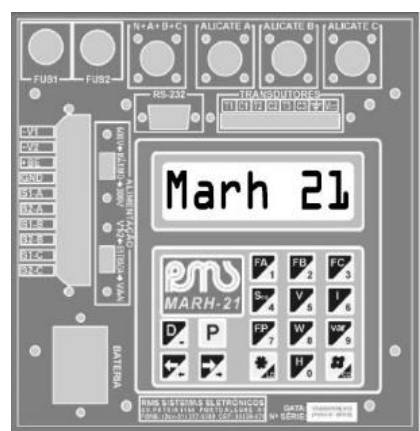

Fig. 1. Power Quality analyzer used to measure.

\section{Measurements laboratory}

For this study, lab was used in a set of three different types of LED lamps, various active powers, which were analyzed separately, as shown in Table II. Thereafter, measurements were made through the use of electrical quantities and power quality analyzers meter to evaluate the reactive power flow behavior of electronic charges in the electric system bus. Studies of both reactive compensation were conducted, as the power quality.

Table II. - Characteristics Of Lamps

\begin{tabular}{|c|c|c|}
\hline TYPE LED LAMP & $\begin{array}{c}\text { POWER } \\
(\mathrm{W})\end{array}$ & $\begin{array}{c}\text { VOLTAGE } \\
(\mathrm{V})\end{array}$ \\
\hline Tubular & $20 \mathrm{~W}$ & $220 \mathrm{~V}$ \\
\hline Compact & $10 \mathrm{~W}$ & $127 \mathrm{~V}$ \\
\hline Compact & $12 \mathrm{~W}$ & $127 \mathrm{~V}$ \\
\hline
\end{tabular}

Initially, measurements were made of waveforms of voltages, currents, as well as active and reactive power and power factor in different types of LED lamps, usually present in Consumer Units of groups A and B. The forms of the voltage and current waves in laboratory bus that feeds the tubular 20W LED lamp and 220V are shown in Fig. 2, where it can be seen that the shape of the voltage waveform is almost sinusoidal. The current waveform showed the presence of harmonic positive sequence current, negative and zero, as the current harmonic spectrum shown in Fig. 3.

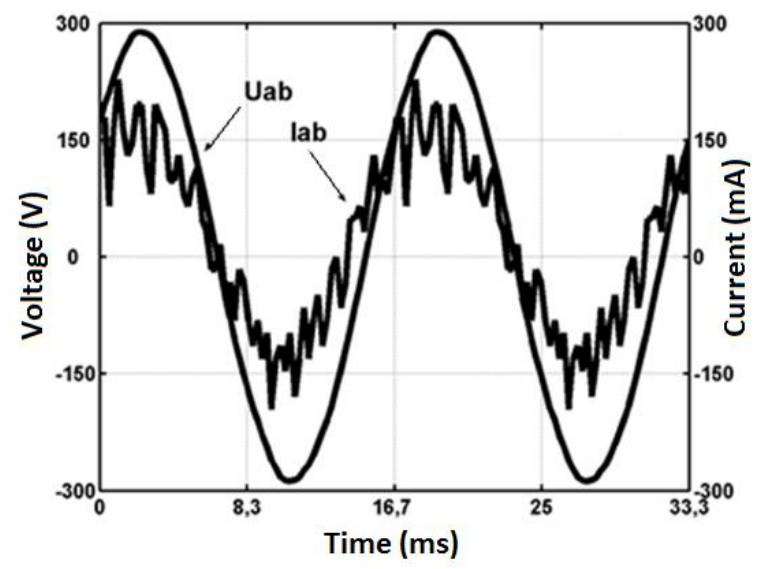

Fig. 2 - Waveforms of voltage and current of the tubular 20W LED lamp, measured in laboratory.

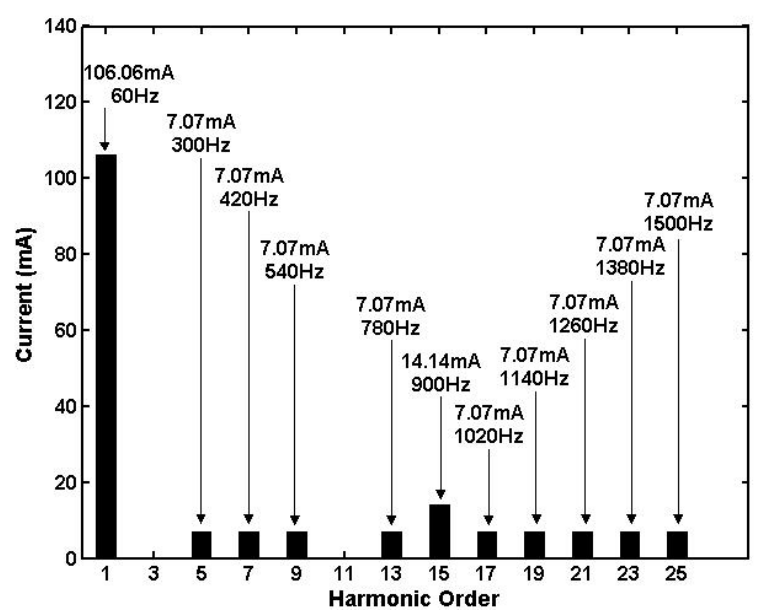

Fig. 3. Harmonic current spectrum of tubular LED lamp $20 \mathrm{~W}$.

The fig. 4 illustrates the phasor diagram of voltage and current that powers the LED lamp, obtained by Fluke power quality analyzer. To note that the current leads in relation to the tension.

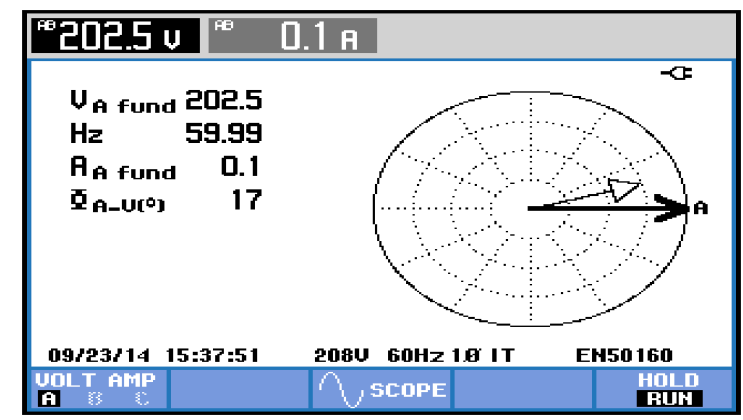

Fig. 4. Vector diagram of voltage and current that feeds the tubular LED lamp 20W.

The fig. 5 shows the flow of active and reactive powers on the bus that feeds the tubular LED lamp features a 20W absorbing active power and a 20VAr injection capacitive reactive power. The fig. 5 also illustrates the difference between the offset factor that represents the cosine of the angle of current and voltage at $60 \mathrm{~Hz}$ (DPF), whose value is 0.95 , and the power factor (PF) that takes into account all frequencies present in the form of the current waveform, which is a much smaller value and equal to 0.65 . The relationship between active power injected into and withdrawn from the bus reactive power is shown in Fig. 6.

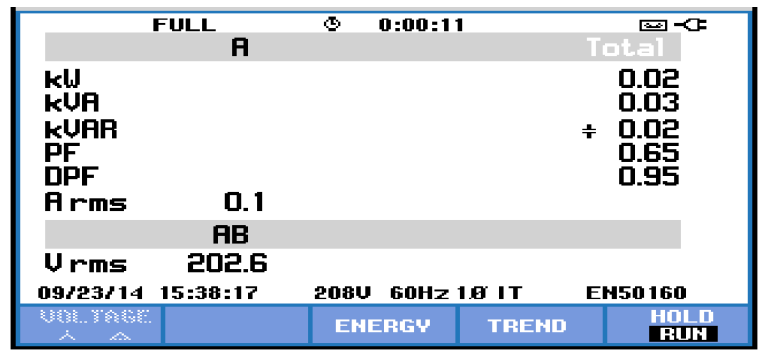

Fig. 5. Captured from power quality analyzer Fluke screen indicating the capacitive reactive power characteristic injected into the system for tubular LED lamp 20W. 


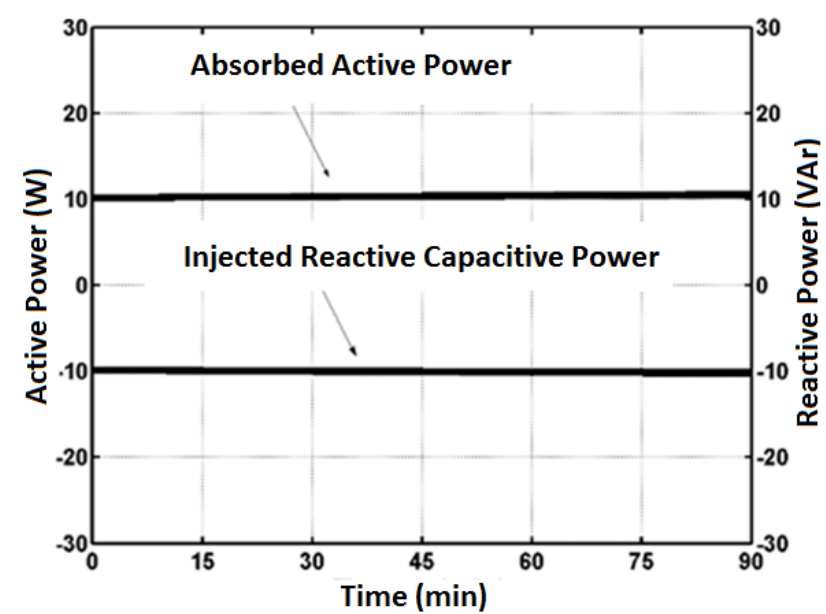

Fig. 6. Absorbed active power and reactive power injected by capacitive tubular LED lamp $20 \mathrm{~W}$ in power bus system.

Continuing in behavior analysis of power quality and reactive flow of electronic loads connected to a bus, a compact LED lamp $10 \mathrm{~W}$ and $127 \mathrm{~V}$ bought off the shelf from a manufacturer that has the seal of Inmetro was analyzed.

The fig. 7 illustrates the waveforms of the voltage and current requested by the lamp to the bus. The waveform voltage does not show significant harmonic distortion, since the shape of the current shows a strong presence of harmonic sequences positive, negative and zero as is illustrated in the harmonic spectrum of current Fig. 8.

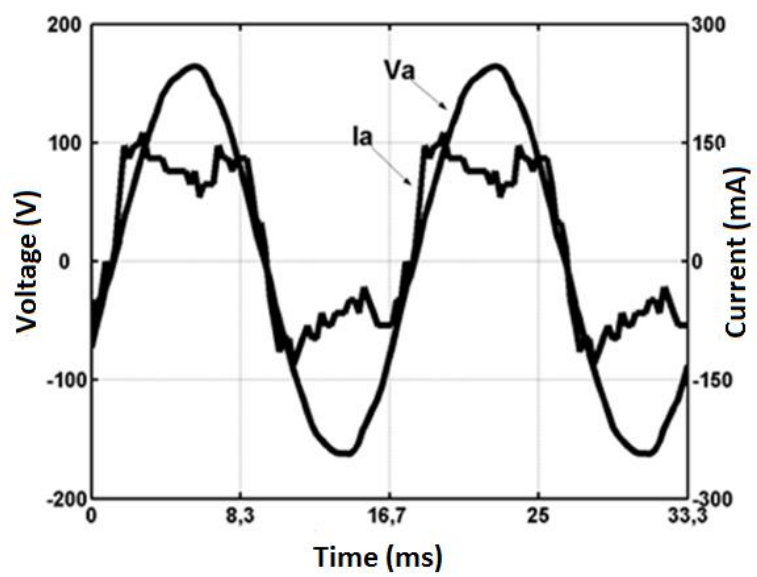

Fig. 7. Current Waveform Phase "a" relative to the voltage 10W compact LED lamp.

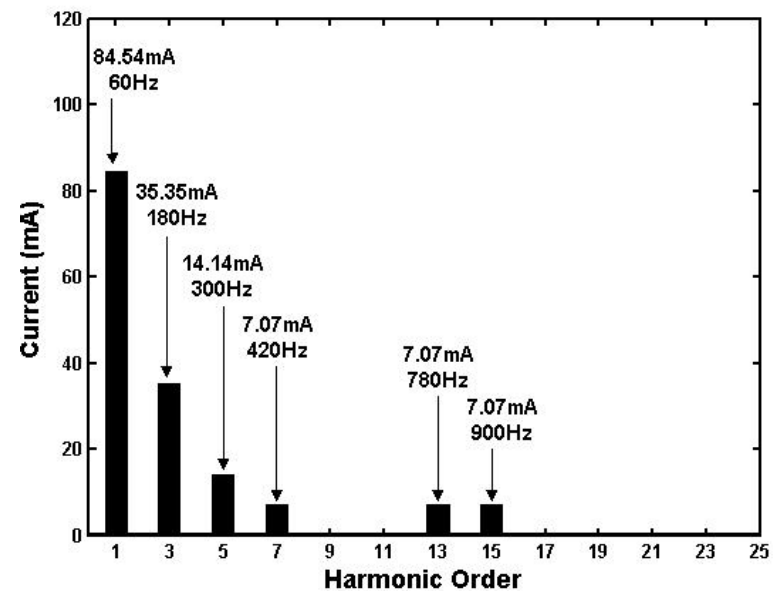

Fig. 8. Harmonic spectrum of current compact 10W LED lamp.
In the phasor diagram between voltage and current shown in Fig.9, it is clear that the current leads toward tension. In this way, there is the capacitive characteristic of LED lamp, proven in Fig.10 by the image removed from the power quality analyzer.

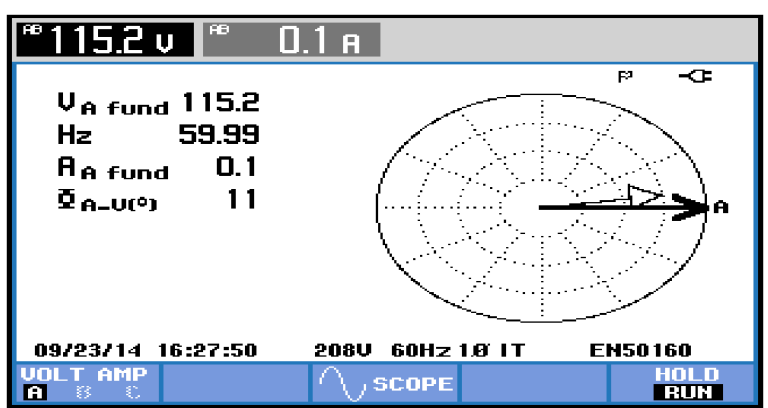

Fig. 9. Phasor diagram between voltage and current that feeds the compact LED lamp 10W.

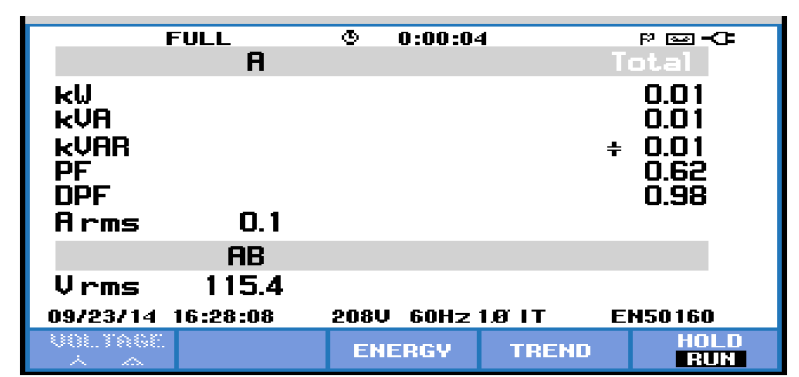

Fig. 10. Screen Captured from power quality analyzer Fluke indicating the capacitive reactive power characteristic injected into the system for compact LED lamp 10W.

They are illustrated in Fig.11: the absorbed active power and reactive power injected into the bus by the LED lamp. We can see in this chart, which absorbed active power is equivalent to injected reactive power.

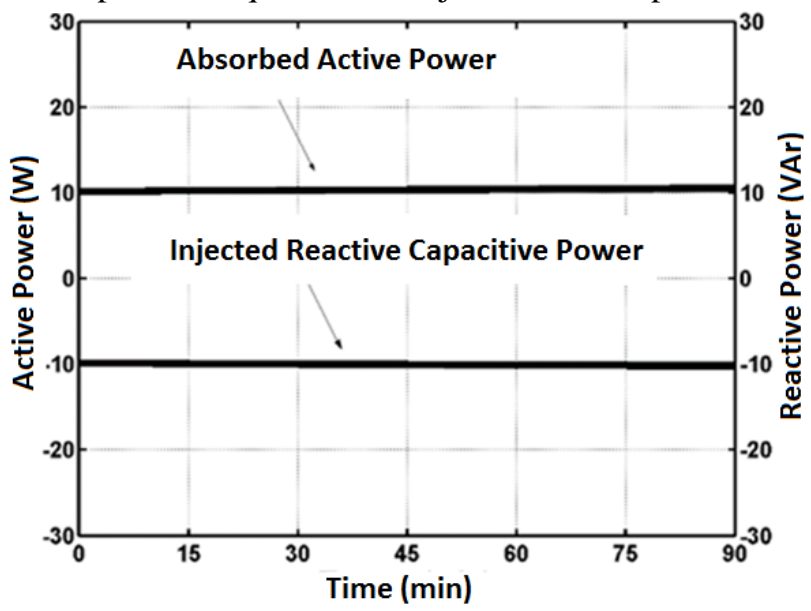

Fig. 11. Absorbed active power and capacitive reactive power injected by the compact LED lamp $10 \mathrm{~W}$ in power bus system.

For a differentiated analysis, a measurement through the power quality analyzer was held in a compact LED lamp $12 \mathrm{~W}$ and $127 \mathrm{~V}$ found on the parallel market.

Again, the forms of current and voltage waves applied to the bus by the lamp were analyzed, as shown in Fig. 12. It was found that, similarly to the previous measurement, the waveform of the voltage does not 
present significant harmonic distortion, while the waveform of current showed strong harmonic content of positive sequence, negative and zero, illustrated in the harmonic spectrum of Fig.13. The current high harmonic content observed can be explained by the absence of filter in certain manufacturers compared to the lamp manufacturers that have a quality control.

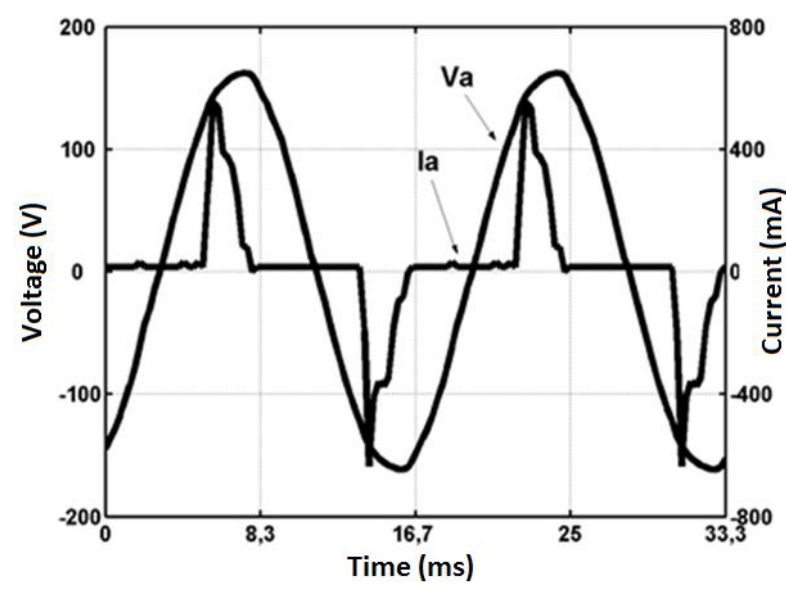

Fig. 12. Forms of voltage and current waves of compact LED lamp $12 \mathrm{~W}$ the parallel market.

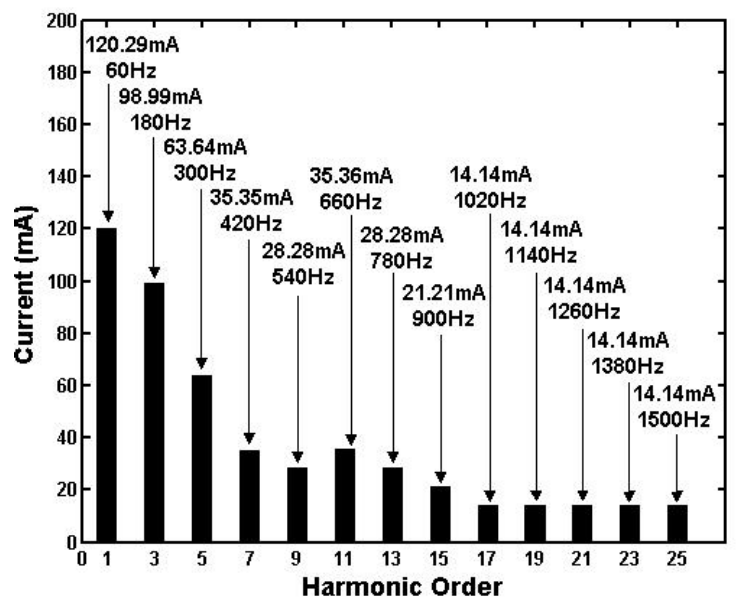

Fig. 13. Harmonic current spectrum of compact LED lamp 12W the parallel market.

According to Fig. 14, which illustrates the phasor diagram of voltage and current that feeds the compact LED lamp $12 \mathrm{~W}$ obtained in power quality analyzer, it is clear that the current leads in relation to voltage, showing a capacitive characteristic. This feature is enhanced through the screen in Fig.15 withdrawn from Fluke power quality analyzer.

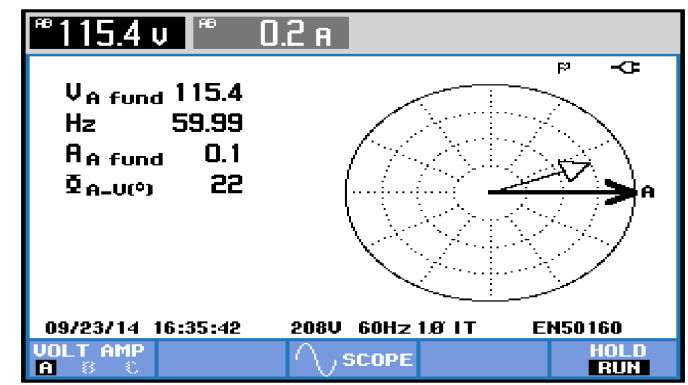

Fig. 14. Phasor diagram of voltage and current that feeds the compact LED lamp $12 \mathrm{~W}$ the parallel market.

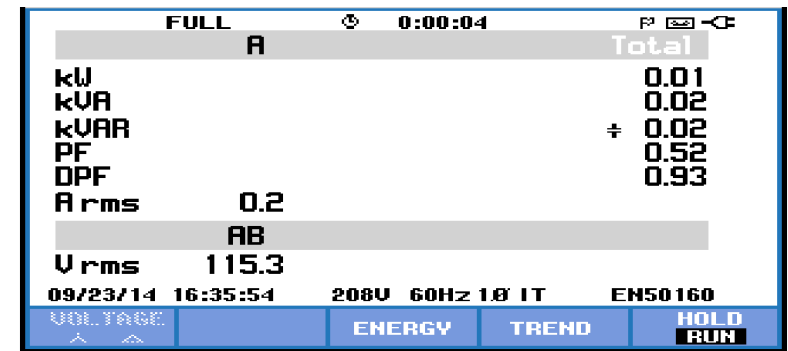

Fig. 15. Captured from power quality analyzer Fluke screen indicating the capacitive reactive power characteristic injected into the system for compact LED lamp $12 \mathrm{~W}$ the parallel market.

Observing the characteristic of active and reactive power in this particular type of electronic load, it is evident through the screen of Fig.15 and Fig.16 the chart, a greater reactive power injection in the analyzed system bus in relation to power active absorbed by the lamp.

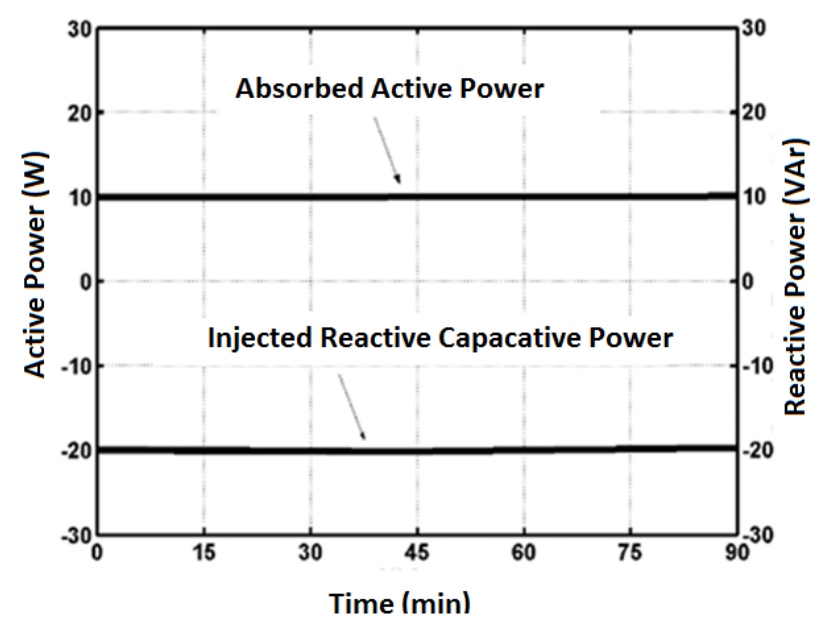

Fig. 16. Absorbed active power and capacitive reactive power injected by the compact LED lamp $12 \mathrm{~W}$ the parallel market in the power bus system.

Analyzing the results obtained in relation to power quality, it was observed that the parallel market LED lamp submitted a total harmonic current distortion around $130 \%$, much higher than the distortion present for the official market LED lamp that was in around $70 \%$. This can lead to a significant increase in effective real current value, due to strong presence of harmonic positive sequence, negative and zero in the LED lamp of the parallel market. Also a significant increase in zero sequence harmonics can cause an increase in the current of neutral systems where these lamps are connected. As for the reactive power injection capacitive on the bus, the electronic loads constituted by LED lamps, both tubular, the compact, they can improve the power factor in eighteen hours of induction time, which requires that the power factor is above 092 induction, providing a reduction of reactive power surplus charged of Consumer Units of Group A will be shown. However, the six additional hours, which requires that the power factor is above 0.92 capacitive, capacitive feature of these electronic loads injecting reactive on the bus, can increase surplus billed reactive energy of Consumer Units, also in Group A. 


\section{Conclusion}

In this article we analyzed the influence of electronic loads in the quality of energy and charging system when connected on the buses of consumer units in groups B and A. In laboratory experiments tubular and compact LED lamps were used with strong non-linear characteristics. Through the data recorded in the power quality analyzers observed a capacitive reactive flow to the power bus. The nonlinearity of electronic loads provided a high current distortion, with the significant presence of harmonic sequences positive, negative and zero, which can raise the effective value of the current phases of the bus and the neutral conductor through the circulation of harmonic sequence zero. Therefore, the bus bar of the electrical systems Consumer Units of groups B and A which have a large number of electronic loads must be constantly monitored to verify the heating conditions of the phase conductors and the neutral due to the presence of multiple streams frequency injected. Injection capacitive reactive power at the bus by electronic loads can contribute to changing the power factor of consumer units and consequently influence the reactive power surplus calculation, both inductive time, as the capacitive time. Is important to remember that, as well as LED lamps used for analysis in this paper, compact fluorescent lamps also have strong nonlinearity and injection capacitive reactive on the bus. Both technologies have been recommended to consumers of group B and A, for replacement of incandescent bulbs, in order to contribute to greater electrical efficiency, regarding the active power consumption. Finally, there is the need for further study on the impact of reactive injection by electronic loads in Units Consumers group B and A and the influence of those in power charging system. In addition, studies should also include analysis of the interference of the multiple frequencies of the current injected by non-linear electronic loads in Consumer Units and buses of distribution concessionaire of energy.

\section{REFERENCES}

[1] Bullough, J. D. "Lighting Answers: Led Systems". National Lighting Product Information Program, Lighting Research Center, Rensselaer Polytechnic Institute. Vol. 7, Issue 3, 2003..

[2] ANEEL. Electricity Distribution procedures in the National Electric System (Prodist), module 8.

[3] IEEE Task Force, "The Effects of Power System Harmonics on Power System Equipment and Loads", IEEE Trans. Power App. and Systems, vol. 104, no. 9, Set. 1985, pp. 2555-2563.

[4] Castro, A. G.; Muños, A. M.; Bollen, M.. "Study harmonics in lamps with use of standard IEC 61000-3-6". Magazine Modern Electricity. Ed. 479. pp. 110 - 117. Feb. 2014. 